\title{
Anaesthetic Management of a Giant Cervico-Occipital Meningocele with Cleft Palate
}

\author{
Mansi Jain ${ }^{1}$, Niti Dalal ${ }^{2}$, Charu Bamba ${ }^{3}$ \\ ${ }^{1}$ Senior Resident, Department of Anaesthesiology and Critical Care, VMMC and Safdarjung Hospital, Ansari Nagar, New Delhi, India, ${ }^{2}$ Assistant Professor, \\ Department of Anaesthesiology and Critical Care, VMMC and Safdarjung Hospital, Ansari Nagar, New Delhi, India, ${ }^{3}$ Consultant, Department of \\ Anaesthesiology and Critical Care, VMMC and Safdarjung Hospital, Ansari Nagar, New Delhi, India.
}

\section{Abstract}

Meningocele is herniation of meninges and CSF through the skull and vertebral defect. The major anaesthetic challenges encountered in management of cervico-occipital meningocele include difficulty in securing airway, proper positioning of the neonate without pressure on the meningocoele sac, maintaining prone position and prevention of electrolyte disturbances and hypothermia. Associated congenital anomalies also can cause anaesthesia and procedure related complications. We report a case of 25 day old neonate with giant cervico occipital meningocele with cleft palate posted for excision and repair.

Keywords: Anaesthetic challenges, meningocoele, prone positioning.

Corresponding Author: Dr. Niti Dalal, Assistant Professor, Department of Anaesthesiology and Critical Care, VMMC and Safdarjung Hospital, Ansari Nagar, New Delhi, India.

Email: drmansi_jain22@yahoo.com

Received: January 2020

Accepted: January 2020

\section{Introduction}

Cephalocoele is a complex congenital anomaly occurring due to neural tube defect during first month of gestation. The term cephalocoele are divided into four types: meningocoele, meningoencephalocoele, atretic encephalocoele and gliocele. Meningocoele is a hernial protusion of part of meninges and CSF in a sac through the defect in skull or vertebrae. Neurologic deficits are present at birth and are dictated by the level of the lesion. Paralysis and sensory deficits can occur below the level of the lesion. It can be associated with other congenital anomalies such as intestinal malrotation, renal anomalies, cardiac malformations and tracheoesophageal fistula. ${ }^{[1]}$

\section{Case Report}

We report a 25 day old neonate who presented with a huge cystic swelling on the posterior aspect of neck and was scheduled for emergent surgical excision and repair. The neonate had been delivered by emergency caesarean section at term in a government hospital. Baby had a birth weight of $3.5 \mathrm{~kg}$ with an APGAR score of 9. The baby had been accepting breast feeds well since birth and passing urine and stools regularly. No neurological deficits had been noted. Baby had a cleft palate. No other obvious congenital anomaly was observed. Cardiovascular and respiratory system examination was found to be normal. The swelling was present since birth and gradually increased to the size of
$13 \times 12 \mathrm{~cm}$. Severely limited neck extension was noted due to the swelling and absent cervical vertebrae elements. MRI Brain showed a $6 \times 4 \mathrm{~cm}$ bony defect posteriorly in the occipital bone and posterior elements of cervical vertebrae with herniation of a large $12 \times 10 \mathrm{~cm}$ CSF sac through the defect. No herniation of any brain tissue was noted. These imaging feutures were suggestive of a cervico-occipital meningocele. Laboratory investigations were within normal limit. Case was posted for emergency surgery the previous day. However surgery was deferred due to inability to intubate. We received this baby the following day. It was decided to perform anaesthesia and surgery in presence of a consultant in view of previous failure.

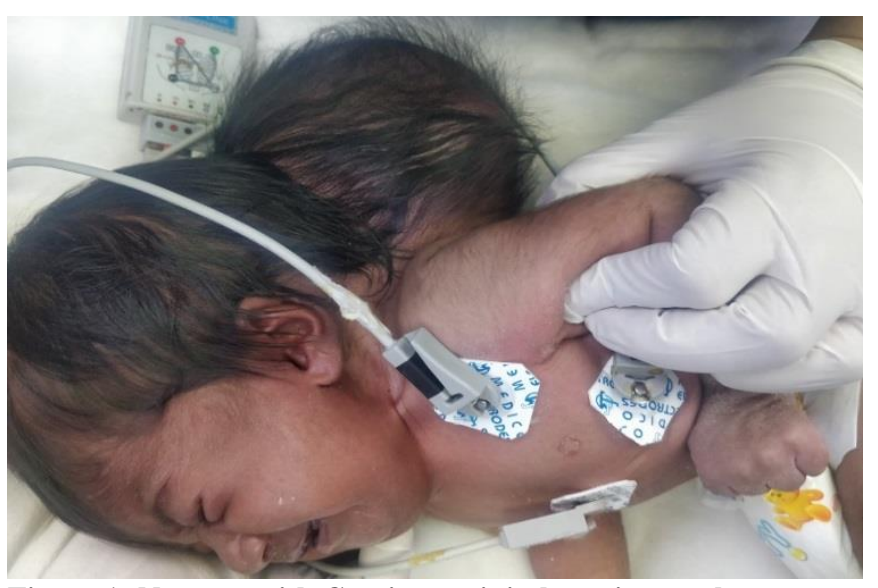

Figure 1: Neonate with Cervico-occipital meningocoele 


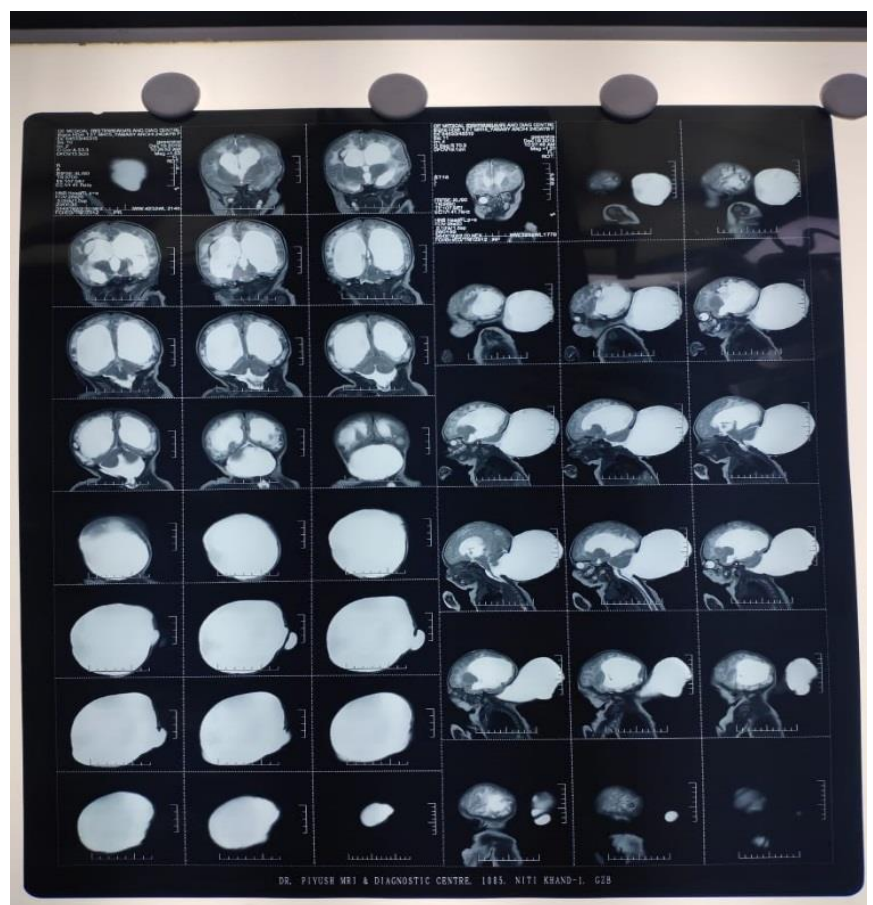

Figure 2: MRI picture

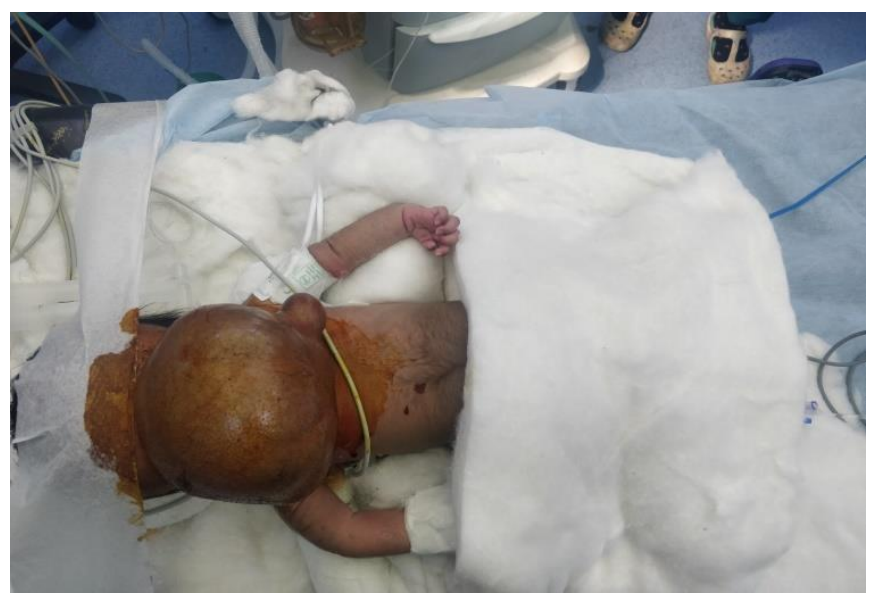

Figure 3: Neonate in prone position

Baby was kept NPO for four hours on day of surgery and ringer lactate was started at the rate of $14 \mathrm{ml} / \mathrm{hr}$. We planned for intubation with cMAC in lateral position. Head and neck was supported by an adequately sized head ring in lateral position. Baby was premedicated with Inj fentanyl $3 \mathrm{mcg}$ iv and induced with Inj propofol $6 \mathrm{mg}$ iv and inhalational sevoflurane at $2 \%$. After adequate mask ventilation was confirmed, cmac guided intubation with the help of optimum external laryngeal maneuver was successfully performed by consultant anaesthesia on first attempt. Baby was intubated with $3.5 \mathrm{~mm}$ internal diameter uncuffed endotracheal tube, fixed at $9 \mathrm{~cm}$ and inj atracurium $1.5 \mathrm{mg}$ iv was given. Position of endotracheal tube was confirmed using a Fiberoptic Bronchoscope. After proper tube fixation and eye care, baby was made prone with extreme care to prevent accidental extubation. Anaesthesia was maintained using $\mathrm{O} 2+\mathrm{N} 2 \mathrm{O}+\mathrm{Sevo}+$ atracurium. Complete resection of the meningocele was achieved without any complication. Approx $250 \mathrm{ml}$ CSF was drained during the surgery. $120 \mathrm{ml}$ blood was lost which was replaced. Hypothermia was avoided by using warm fluids, warming blanket and continuous temperature monitoring. Post op an ABGA was done to ensure optimum ventilation and electrolyte balance. Duration of surgery was 2 hours. After adequate reversal of neuromuscular blockade, baby was extubated. Baby was awake, crying, moving all 4 limbs. Baby was discharged on 10 th postoperative day. At present (postoperative 2 months) baby is doing well without any neurodeficit as followed up in Neurosurgery OPD.

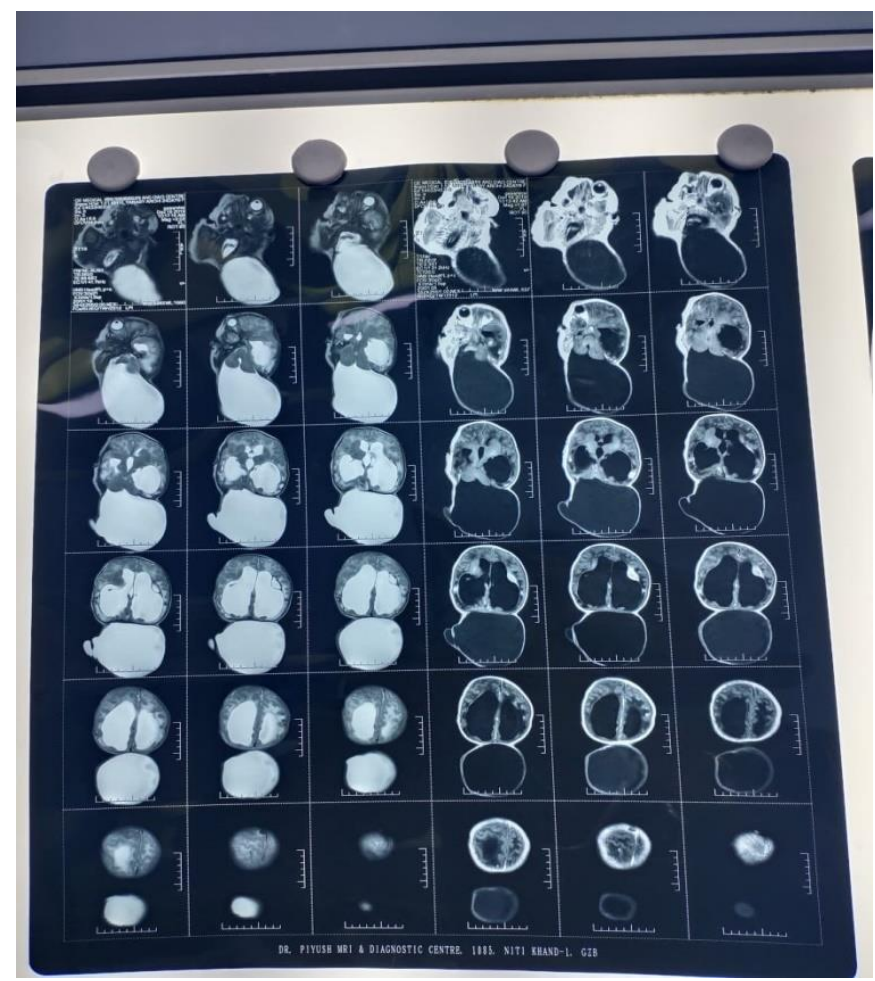

Figure 4: MRI picture

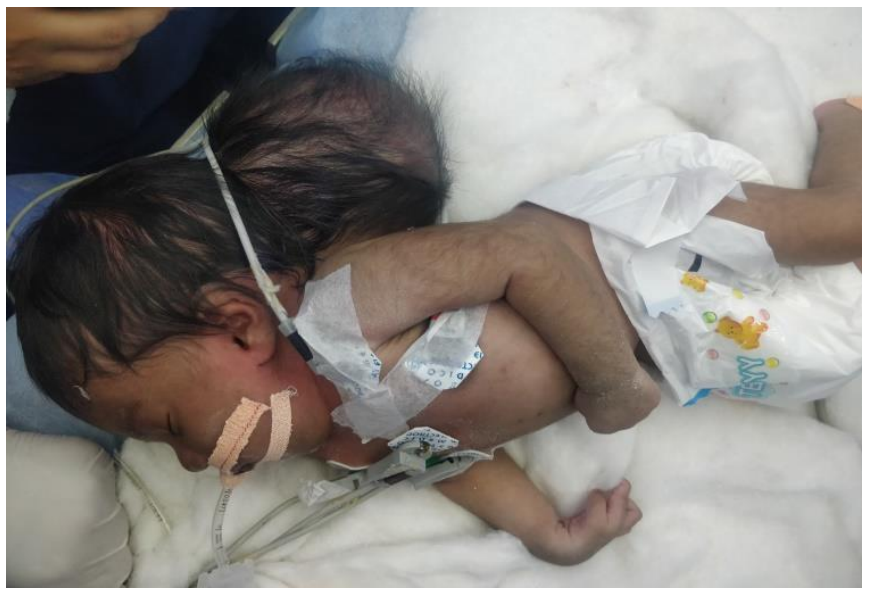

Figure 5: Neonate after intubation in lateral position

\section{Discussion}

Cranial meningocele refers to the herniation of meninges through a bony defect in the skull and meningomyelocele contain neural elements along with the meninges in the herniated sac. ${ }^{[2]}$ An encephalocele contains elements of brain tissue also within the sac. The defect is more often in the occipital bone ${ }^{[3]}$ A perioperative plan must be formulated by 
the anaesthetist based on airway management, prevention of hypothermia, fluid balance and maintainence of prone position. Main aims should be to avoid premature rupture of the meningocoele and to manage a possible difficult airway due to restricted neck movement and inability to achieve optimal position for endotracheal intubation. ${ }^{[4]}$

Airway management of neonates and pediatric population is difficult compared with adult due to anatomic variations such as short neck, large tongue and large head. Also paediatric patients have low functional reserve volume and failure to intubate may result in hypoxaemia, bradycardia and even cardiac arrest.Difficult airway cart with ventilation masks, tracheal tubes, airways, scope blades etc., should be kept ready. Devices for maintaining normothermia like circulating warm-air devices, airway humidifiers, fluid warming devices should be kept ready. ${ }^{[5]}$

Airway management of occipital meningocele children were explained by various authors. Intubation can be attempted in one of the ways described below:

- Lateral position ${ }^{[6]}$

- In supine position with sac protected by elevating it on a doughnut shaped support. ${ }^{[7]}$

- In supine position after getting the child' $s$ head beyond the edge of the table with an assistant supporting the head while other assistant stabilizes baby s body. ${ }^{[8]}$

- Quezado et al and Mowafi et al have put blanket below baby trunk with the head hanging from the edge of the table to facilitate intubation in such patients. ${ }^{[9,10]}$

- Manhas et al took aid to lift the child (one person to support the head and shoulder and a second person to lift the torso and legs) for intubation. ${ }^{[1]}$

- Dey et al used a third person to extend the neck to successfully intubate a neonate. ${ }^{[12]}$

Needle decompression of meningocele sac, under sterile precaution has also been proposed. ${ }^{[8]}$ However the resultant rapid decompression of ventricular system may result into fatal complications like cardiac arrest due to traction of cerebral neuronal pathways. Other aids like Laryngeal mask airway, Video Laryngoscope are being used to facilitate intubation in neonates in difficult situations. Only after checking for adequate mask ventilation, NMB agents should be administered. We intubated our patient after induction with propofol and sevoflurane. Relaxation was maintained with atracurium throughout the surgery as nerve stimulation was not sought by the surgeon.

Children with meningocele have increased incidence of latex allergy which can manifest as intraoperative cardiovascular collapse and bronchospasm. Intraoperative neurological insult can present with immediate postoperative seizures. Intensive monitoring of blood loss and its replacement is must. CSF drainage can cause volume and electrolyte disturbances which need to be managed. Other concerns that need the anesthesiologist's attention in patients with occipital encephalocoele are raised intracranial pressures, low cerebral perfusion pressures, disturbances in central autonomic control and temperature regulation in these children. Creighton et al in a series of 31 patients with occipital encephalocele have observed disturbances in central autonomic control and defective temperature control in these children. ${ }^{[6]}$ Thus attention has to be given to blood loss, maintanence of body temperature, prone position and its associated complications and careful securing of endotracheal tube. Despite the difficulties, intubation and anaesthetic management in our patient was successfully achieved.

\section{Conclusion}

Perioperative management of patients with giant meningoencephalocele may be challenging for both anaesthesiologist and neurosurgeon. Managing a case of meningoencephalocele includes looking for other congenital abnormalities, expertise in handling airway, and intraoperative care mainly involving proper positioning, monitoring body temperature and blood loss replacement. These patients must be managed closely with an interdisciplinary approach. Careful planning and perioperative management are essential for successful anaesthetic management of these patients.

\section{References}

1. Neeta S, Upadya M, Pachala SS. Anesthetic management of a newborn with occipital meningocele for magnetic resonance imaging. Anesth Essays Res 2015;9:238-40

2. Walia B, Bhargava BP, Sandhu K. Giant occipital encephalocele. MJAFI 2005;61:293- 4.

3. Yıldurum ZB, Avci E, Torun F, Cengiz M, Cigdem A, Karabag H, et al. Airway management for occipital encephalocele in neonatal patients: A review of 17 cases. J Neurosci Rural Pract 2011;2:159- 61.

4. Kumar R, Jain S, Mehta RK, Trivedi S, Dakshayani KR. Anaesthetic Management of Giant Encephalocele. Int J Res Med Sci. 2015;3:3889. 92.

5. Hackel A, Badgwell JM, Binding RR, Dahm LS, Dunbar BS, Fischer $\mathrm{CG}$, et al. Guidelines for the pediatric perioperative anesthesia environment. American Academy of Pediatrics. Section on Anesthesiology. Pediatrics 1999;103:512- 5.

6. Creighton RE, Relton JES, Meridy HW. Anaesthesia for occipital encephalocele. Can Anaesth Soc J 1974;21:403-6.

7. Cote Charles J, Miller Ronald D. Miller's Anaesthesia, 7th ed., chapter : 82, Paediatric anaesthesia, Churchill Livingstone, 2010, 2589.

8. Walia P, Bhargawa P,Sandhu K. Giant occipital encephalocele. Armed Forces Med J India 2005;61:293-4.

9. Quezado Z, Finkel JC. Airway management in neonates with occipital encephalocele: Easy does it. Anesth Analg. 2008;107:1446-50.

10. Mowafi HA, Sheikh BY, Al-Ghamdi AA. Positioning for anesthetic induction of neonates with encephalocele? The Internet Journal of Anesthesiology. 2001;5(3):34-8.

11. Manhas Y, Chinnan NK, Singh AK. Neonatal airway management in occipital encephalocele. Anesth Analg. 2006;103:1632

12. Dey N, Gombar KK, Khanna AK, Khandelwal P. Airway management in neonates with occipital encephalocele - adjustments and modifications. Pediatric Anesth. 2007;17:1111-21. 
Copyright: () the author(s), 2020. It is an open-access article distributed under the terms of the Creative Commons Attribution License (CC BY 4.0), which permits authors to retain ownership of the copyright for their content, and allow anyone to download, reuse, reprint, modify, distribute and/or copy the content as long as the original authors and source are cited.

How to cite this article: Jain M, Dalal N, Bamba C. Anaesthetic Management of a Giant Cervico-Occipital Meningocele with Cleft Palate. Acad. Anesthesiol. Int. 2020;5(1):01-04.

DOI: dx.doi.org/10.21276/aan.2020.5.1.1

Source of Support: Nil, Conflict of Interest: None declared. 